\title{
Agrookolišni pokazatelji i njihova primjena u Zajedničkoj poljoprivrednoj politici EU (ZPP)
}

\section{Sažetak}

Odnos poljoprivrede i okoliša poprima sve veću pažnju javnosti i traži specifične odgovore javnih politika. $S$ obzirom da donošenje odluka mora biti temeljeno na dokazima potrebno je osmišljavati i promatrati pokazatelje koji služe u kreiranju odgovarajućih mjera poboljšanja odnosa poljoprivrede i okoliša. Rad donosi pregled mjera i odabranih agrookolišnih pokazatelja svih država članica (EU-28) za dostupne godine unutar razdoblja 2012. - 2017. temeljem podataka iz baze Eurostat. Između ostalog, rezultati pokazuju da Hrvatska, Bugarska i Slovenija prednjače u udjelu korištene poljoprivredne površine pod područjima ekološke mreže "Natura 2000". Države članice koje imaju najrazvijeniji sektor poljoprivrede obično vrše i najveći pritisak na okoliš. Tako Nizozemska ima najveći udio korištene energije u poljoprivredi i vrši najveći pritisak na okoliš stočarskom proizvodnjom. Stoga Zajednička poljoprivredna politika (ZPP) nastoji kroz trenutnu reformu razraditi adekvatne $i$ kompromisne agrookolišne mjere za predstojeće razdoblje 2021. -2027.

Ključne riječi: poljoprivreda, okoliš, mjere, pokazatelji, Zajednička poljoprivredna politika (ZPP)

\section{Uvod}

Razvoj poljoprivredne politike prati rastuća potreba neprestane procjene ili provjere učinaka mjera. U svojoj osnovi usmjerena je na sigurnost opskrbe hranom s ciljem osiguranja stabilnog dohotka poljoprivrednicima koji bi trebao odgovarati prosječnim vrijednostima dohodaka u drugim granama gospodarstva. Povijesne okolnosti mijenjale su usredotočenost i opus mjera poljoprivrednih politika svih zemalja kako zbog zahtjeva Svjetske trgovinske organizacije (eng. World Trade Organization -WTO), tako i potrošača. Uloga WTO-a je osigurati da trgovinski odnosi između zemalja članica budu pošteni i transparentni, a trgovina što više liberalizirana te spriječiti da domaće potpore izazivaju poremećaje na svjetskom tržištu. S druge strane potrošači su posljednjih desetljeća postali osjetljiviji na pitanja održive poljoprivredne proizvodnje i zahtijevaju od donositelja odluka da se javnim novcem subvencioniraju mjere koje će smanjiti negativni utjecaj poljoprivrede na okoliš. U okviru ZPP-a prve agrookolišne mjere se primjenjuju od polovice 1970- tih i sa svakom sljedećom reformom se umnožavaju i intenziviraju (Mikuš i sur., 2019.) ZPP je kroz svojih pet reformi od početka devedesetih, a osobito posljednjom (CAP post 2013) prilagodila svoj okvir mjera i povećala sredstva za ekonomsku, društvenu i ekološku održivost kao i uravnoteženi teritorijalni razvoj (Kelly i sur., 2018).

S obzirom na sve veće potrebe za izvještavanjem u svrhu boljeg planiranja, provedbe, procjene i vrednovanje učinaka politike, postojeći sustavi nadzora i prikupljanja podataka također se moraju razvijati sukladno novim temama politike. Općenito, pokazatelji su alati za prikupljanje i organiziranje znanja, a istovremeno izraz su društvenih i političkih standarda i prioriteta (Rametsteiner i sur., 2011). Potrebni su za procjenu ciljeva, evaluaciju mjera ili opisivanje situacija. Prema Wieck i sur., 2019. obilježja dobrog pokazatelja su da je mjerljiv, osjetljiv na prostornu i vremensku promjenu, troškovno prihvatljiv i dostupan, razumljiv za interpretaciju, 
pouzdan, ponovljiv, odgovara interesima ciljanih korisnika, specifičan, vremenski točan, odgovara postavljenim ciljevima i znanstveno ispravno postavljen. Kao što je vidljivo iz nabrojenog, pokazatelj mora ispuniti mnogo kriterija koje je teško postići jer prikazuje složen proces na pojednostavljen način (Wilson i Buller, 2001.).

U kontekstu okolišnih pokazatelja OECD, 2001. nudi sljedeću definiciju:,Agrookolišni pokazatelj sažeto je mjerilo koje kombinira sirove podatke o stanju okoliša, rizika za okoliš, promjene u okolišu ili pokretačke snage takve promjene, a koja se može u cijelosti pripisati ili dijelom poljoprivrednoj aktivnosti ili aktivnostima." Pokazatelji služe kao instrument za donositelje odluka i za procjenu međunarodne i nacionalne implementacije politike. Postoje brojne studije i prijedlozi agrookolišnih pokazatelja na globalnoj i razini EU, stoga je cilj ovog rada dati pregled agrookolišnih pokazatelja s fokusom na razini članica EU i s obzirom na agrookolišne mjere koje donosi Zajednička poljoprivredna politika.

\section{Materijali i metode}

Za provedbu ovog istraživanja korištena je sekundarna analiza podataka. Literaturni izvori odabrani su temeljem pretraživanja baze Google Scholar prema ključnim riječima: agri-environmental indicators, evaluation, measures, Common Agricultural Policy. Odabrani su radovi zastupljeni u bazama Web of Science, Scopus ili CAB Abstracts te znanstvena priopćenja međunarodnih skupova. Također, korištene su službene publikacije Europske komisije (eng. European Commission - EC), Organizacije za ekonomsku suradnju i razvoj, eng. Organisation for Economic Co-operation and Development-OECD), Organizacije za prehranu i poljoprivredu (eng. Food and Agricultural Organization - FAO) i Europske agencije za okoliš (eng. European Environment Agency - EEA). Za prikaz i usporedbu odabranih agrookolišnih pokazatelja na razini država članica EU korištena je baza statističkih podataka Eurostat.

\section{Rezultati i rasprava}

\section{Agrookolišne mjere}

Veza poljoprivredne proizvodnje i prirodnog okoliša je uska i vrlo kompleksna. Poljoprivreda oblikuje krajobraz, pozitivno utječe na prevenciju prirodnih katastrofa (poplave, suše, požari), a negativno putem erozije i degradacije tla, deforestacije, onečišćenja voda i emisije štetnih plinova(Matthews, 2013).Zajednička poljoprivredna politika (ZPP) nastoji putem pravila i potpora potaknuti i nagraditi poljoprivrednike za očuvanje prirodnih resursa i osiguravanje javnih dobara. Agrookolišne mjere su definirane kroz oba stupa ZPP-a. Prvi stup uključuje pravila i obvezne standarde za sve poljoprivrednike u okviru mehanizma višestruke sukladnosti. Višestruka sukladnost se sastoji od dva elementa: 1. Obavezni zahtjevi za upravljanje (SMR) koji obuhvaćaju 18 zakonodavnih normi iz područja okoliša, sigurnosti hrane, zdravlja životinja i biljaka te dobrobiti životinja koje poljoprivrednik mora poštovati i 2. Dobri poljoprivredni i okolišni uvjeti (GAEC) koji se odnose na niz normi vezanih uz zaštitu tla, održavanje organske tvari i strukture tla, očuvanje staništa i upravljanje vodama. Zahtjevi koji spadaju pod višestruku sukladnost su osnovne agrookolišne mjere i troškove ispunjenja zahtjeva snosi poljoprivrednik po principu onečišćivač plaća (eng. polluter pays principle). Višestruka sukladnost tako predstavlja instrument putem kojeg se okolišni zahtjevi integriraju u ZPP osiguravajući da potpore doprinose promicanju održive poljoprivrede što je ujedno i odgovor na rastući pritisak javnosti.

Od 2014. godine u okviru prvog stupa se primjenjuju i zelena plaćanja (eng. greening) kao svojevrsna inovacija ZPP-a u motivaciji poljoprivrednika da obavljaju prakse korisne za klimu i okoliš kroz tri mjere (Gocht i sur., 2017): raznolikost usjeva, očuvanje trajnih travnjaka i ekološki značajne površine. Raznolikost usjeva podrazumijeva da je poljoprivrednik u sustavu programa izravnih plaćanja s više od 10 ha obradivog zemljišta dužan uzgajati različite vrste usjeva, 
pri čemu glavna kultura ne smije prelaziti više od 75 \% površine. Očuvanje trajnih travnjaka se odnosi na zabranu prenamjene travnjaka ako su smješteni u područjima obuhvaćenim ekološkom mrežom „Natura 2000“. Natura 2000 je ekološka mreža sastavljana od područja važnih za očuvanje ugroženih vrsta i staništa. Stoga, poljoprivrednici na područjima unutar Natura 2000 ne smiju preorati niti prenamijeniti travnjake, pašnjake, livade i krške pašnjake u drugu vrstu korištenja (npr. pretvoriti ih u oranice i slično), već trajno čuvati i koristiti kao livade ili pašnjake koji su svrstani pod zajednički pojam,,trajni travnjaci". Također, udio travnjaka u ukupnoj poljoprivrednoj površini se ne smije smanjiti za više od 5 \% u odnosu na referentnu 2015. godinu. Ekološki značajne poljoprivredne površine moraju održavati poljoprivrednici koji imaju više od 15 ha obradive površine (oranice, staklenika, plastenika). Pod takve površine spadaju kulture koje fiksiraju dušik, ugar, obilježja krajobraza, postrni usjevi, zeleni pokrov i sl.

Kroz drugi stup ZPP-a financirane su mjere ruralnog razvoja koje uključuju nagradu i poticaj poljoprivrednicima koji se dobrovoljno angažiraju za postizanje okolišnih ciljeva. Prihvaćanjem određenih praksi koje doprinose ublažavanju nepovoljnog učinka poljoprivrede na okoliš te potiču bioraznolikost i očuvanje genetskih resursa značajnih za poljoprivredu, nastaju povećani troškovi ili izgubljeni prihod, što je najvažniji argument za kompenzaciju javnim novcem. Mjere drugog stupa kroz koji se može ostvariti takva vrsta potpore su mjera 10-Poljoprivreda, okoliš i klimatske promjene, mjera 11 - Ekološki uzgoj i mjera 13 - Plaćanja područjima s prirodnim ograničenjima. Iako se smatra da je Europska unija (EU) predvodnica u inicijativama i primjeni okolišnih mjera od 1970-tih, poljoprivreda EU-a još uvijek negativno utječe na okoliš. Tako uzrokuje više od $10 \%$ emisije stakleničkih plinova, 44 \% povlačenja vode, osobito u Mediteranskim zemljama, rizik eutrofikacije zbog upotrebe gnojiva i eroziju tla. Posljedično, gubitak bioraznolikosti se ubrzava i postaje iznimno teško postići zaustavljanje takvog trenda do 2020. godine (Recanati isur., 2019).

Prema Bas-Defossez, i Meredith, 2019. u skorijoj budućnosti, točnije reformom ZPP-a koja se odnosi na razdoblje nakon 2020. godine, zemlje članice će samostalno odlučivati o mjerama koje će poduzeti u postizanju zadanih ciljeva vezanih uz klimatske promjene, brigu za okoliš i očuvanje krajobraza te biološku raznolikost. Nove mjere poboljšanja odnosa poljoprivrede i okoliša zamijenit će dosadašnja zelena plaćanja i višestruku sukladnost. Uz postojećih sedam, dodna su još tri uvjeta unutar GAEC-a. Uvjeti su vezani uz klimatske promjene, vodu, zaštitu tla, bioraznolikost i krajobraz. Novost su i obvezne,eko-sheme“ (programe) koje su osmišljene da povećaju nacionalne aktivnosti vezane uz okoliš i klimatske promjene a koje će biti temeljene na lokalnim potrebama i okolnostima. Nadalje, mjere koje se odnose na poljoprivredu okoliš i klimu (eng. Agri-environment-climate measures - AECMs) obvezne su za državu članicu, ali dobrovoljne za poljoprivrednike. Cilj im je obnavljanje, očuvanje i poboljšanje ekosustava; poboljšanje učinkovitosti resursa i promjene prema gospodarstvu niskim udjelom ugljika i klimatskom otpornošću.

Oko 30 \% nacionalnih sredstava za ruralni razvoj bit će namijenjeno okolišnim i klimatskim promjenama, kao i dodatnih 15 \% sredstava koja se mogu prebacivati iz prvog u drugi stup bez nacionalnog sufinanciranja. Očekuje se da će 40 \% ukupnog proračuna ZPP-a biti izdvojeno za djelovanja u području klime.

\section{Agrookolišni pokazatelji i njihova upotreba u Zajedničkoj poljoprivrednoj politici}

Agrookolišni pokazatelji daju uvid u stanje okoliša u kojem se obavlja poljoprivreda, prate utjecaj poljoprivrede na okoliš, služe za procjenu utjecaja poljoprivredne i okolišne politike na održivo upravljanje gospodarstvom, pružaju bazu za donošenje političkih odluka i prikazuju odnos poljoprivrede i okoliša za širu javnost (Wieck i Hausmann, 2019). U svrhu povezivanja agrookolišnih pokazatelja s implementacijom politike već su ranije postojale određene eva- 
luacijske metode u okviru ZPP-a. Tako je za razdoblje 2007.-2013. predstavljen novi integrirani Zajednički okvir za nadzor i evaluaciju (eng. Common monitoring evaluation framework - CMEF) kojim su uvedeni pokazatelji za evaluaciju programa ruralnog razvoja zemalja članica. Nadalje, njegovo poboljšanje i nadopuna rezultirala je u razdoblju 2014.-2020. Zajedničkim okvirom za nadzor i evaluaciju cjelokupnog (stup 1 i stup 2) ZPP-a. Razrađen je temeljem tri glavna cilja ZPP-a (EC, 2015): 1. održiva proizvodnja hrane što podrazumijeva sigurnost opskrbe hranom promicanjem konkurentnosti poljoprivrede EU-a uz osiguravanje načina za suočavanje sektora poljoprivrede s potencijalnim poremećajima na tržištu i s funkcioniranjem prehrambenog lanca, 2. održivo upravljanje prirodnim resursima i odgovor na klimatske promjene kao i očuvanje prirodnih resursa o kojima ovisi poljoprivredna proizvodnja, te 3 . uravnotežen teritorijalni razvoj koji obuhvaća socioekonomski razvoj ruralnih područja uz očuvanje strukturne raznolikosti u cijeloj EU. Pokazatelji koje CMEF obuhvaća su pokazatelji izlaznog proizvoda (npr. koliko je ulaganja financirano kroz jednu mjeru), pokazatelji izravnog i neizravnog učinka (npr. broj radnih mjesta otvorenih jednom investicijom) i pokazatelji utjecaja koji pokazuju dugoročniji učinak (npr. smanjenje stope nezaposlenosti). Općenito, pokazatelji izlaznog proizvoda povezani su s pojedinačnim intervencijama politike, pokazatelji rezultata s posebnim ciljevima, a pokazatelji utjecaja povezani su s općim ciljevima ZPP-a.

Osim socioekonomskih i sektorskih pokazatelja u CMEF-u su definirani pokazatelji drugog stupa kroz Zajednički sustav za praćenje i evaluaciju Common Monitoring and Evaluation System - CMES. Imenovani pokazatelji stanja u okolišu su: zemljišni pokrov, područja s prirodnim ograničenjima, intenzitet uzgoja, područja ekološke mreže „Natura 2000“, indeks populacije čestih vrsta ptica na poljoprivrednim staništima, stanje očuvanosti poljoprivrednih staništa (travnjak), poljoprivredna proizvodnja na području velike prirodne vrijednosti, zaštićene šume, korištenje voda u poljoprivredi, kvaliteta vode, organska tvar u oraničnom tlu, erozija tla vodom, proizvodnja obnovljive energije iz poljoprivrede i šumarstva, potrošnja energije u poljoprivredi, šumarstvu i prehrambenoj industriji i emisija stakleničkih plinova iz poljoprivrede. Za svaki pokazatelj razrađeno je detaljno objašnjenje koje obuhvaća mjernu jedinicu, izvore podataka, na kojoj prostornoj razini se prati, koliko često itd. (EC, 2017.)

Evaluacija mjera poljoprivredne politike je prilika da se procijeni je li primijenjena intervencija odgovarajuća, što ujedno pomaže u donošenju boljih političkih odluka u budućnosti. lako još uvijek traje proces prilagodbe CMEF-a, ipak je podignuta svijest o potrebi i obvezi mjerenja učinaka potrošenog javnog novca. Izvori podataka za pripremu evaluacijskog izvješća o pokazateljima su brojni kao: Eurostat, Sustav računovodstvenih podataka u poljoprivredi (eng. Farm Accountancy Data Network - FADN), Europska agencija za okoliš (eng. European Environment Agency), Glavna uprava za okoliš (eng. Directorate-General for Environment), Ekonomska komisija Ujedinjenih naroda za Europu (eng. United Nations Economic Commission for Europe - UNE$\mathrm{CE}$ ), Organizacija za hranu i poljoprivredu (eng. Food and Agriculture Organization of the United Nations - FAO; Organizacija za ekonomsku suradnju i razvoj (eng. Organisation for Economic Cooperation and Development - OECD), Zajednički istraživački centar (eng. Joint Research Centre- JRC), NATURA, razne nacionalne studije, istraživanja, izvješća te ostale specifične baze podataka koje prate šume, staništa, vrste itd.

\section{Druge značajnije baze agrookolišnih pokazatelja}

Uvidom u službenu statistiku EU-a, Eurostat, vidi se da se razina razvijenosti i aktualnost agrookolišnih pokazatelja razlikuje. Neki su već u upotrebi, njihove definicije i mjerenja su dobro objašnjeni, a podaci su dostupni na nacionalnoj i, prema potrebi, na regionalnoj razini. Ostali pokazatelji su dobro definirani, ali nemaju regionalne ili usklađene podatke ili su njihovi modeli mjerenja manjkavi. S obzirom da neki pokazatelji trebaju znatna poboljšanja da bi po- 
stali potpuno ili ponovno upotrebljivi još nisu uvršteni u bazu Eurostata ili su arhivirani samo za neka prošla razdoblja. Ovdje donosimo kratku kronologiju razvoja agrookolišnih statističkih pokazatelja.

Sporazumom između Europske komisije (EK) i Europske okolišne agencije (EEA) 2000. godine započet je intenzivan rad na razvoju pokazatelja utjecaja poljoprivrede na okoliš za 15 zemalja članica EU. Kao rezultat EK je 2001. godine objavila priopćenje pod nazivom "Statistical Information Needed for Indicators to Monitor the Integration of Environmental Concerns into the CAP" COM(2001), čime je predloženo 35 agrookolišnih pokazatelja. Pokazatelji su poredani prema četiri poglavlja. To su „Odgovori“, „Pokretačke snage “, „Pritisci i koristi“ te „,Stanje/utjecaj“ Poglavlje „Odgovori“ podrazumijeva javne politike, tehnologije te tržišta i ponašanja proizvođača. Nadalje, poglavlje „Pokretačke snage“ sadrži četiri elementa: upotreba input-a, upotreba zemljišta, upravljanje poljoprivrednim gospodarstvom i trendovi. Poglavlje „Pritisci i koristi“ sastoji se od potpoglavlja: onečišćenje, iscrpljivanje resursa i koristi. Naposljetku, poglavlje „Stanje/utjecaj“ sastoji se od potpoglavlja biološka raznolikost i staništa, prirodni resursi i krajobraz. Svi elementi unutar poglavlja sadrže mjerljive pokazatelje (u mjernim jedinicama) koji su prikazani u bazi Eurostata.

Inicijalni skup od 37 pokazatelja razvila je i EAA 2004. godine. Svrha ove baze bila je povisiti kvalitetu, protočnost i geografsku pokrivenost podataka, doprinijeti ostalim inicijativama razvoja pokazatelja i pružiti funkcionalnu i stabilnu podlogu za procjenu napretka prema postavljenim prioritetima okolišne politike. Pokazatelji pokrivaju teme onečišćenja zraka i smanjenje ozonskog omotača, klimatske promjene, otpad, voda, biološka raznolikost i svojstva tla i četiri sektora: poljoprivreda, energija, transport i ribarstvo.

Prema autorima (Kim i sur., 2013) OECD je u suradnji s Eurostatom i FAO-om razvio širok spektar agrokolišnih pokazatelja koji su predstavljeni kroz izvješće The OECD Compendium of Agri-environmetal indicators za 35 zemalja članica OECD-a. Njihova svrha je da posluže kao informacija donositeljima odluka i široj javnosti o trenutnom stanju i promjenama uvjeta okoliša u poljoprivredi kao i za bolje razumijevanje veza između uzroka i utjecaja poljoprivrede, reforme poljoprivredne politike, liberalizacije trgovine i ekoloških mjera na okoliš. Također, služe kao pomoć u ispravnim reakcijama na promjene u uvjetima zaštite okoliša te doprinose učinkovitom praćenju i procjeni učinkovitosti politika koje se bave poljoprivredno-okolišnim problemima, promiču održivu poljoprivredu, uključujući buduće perspektive poljoprivrednookolišnih veza. Agrookolišni pokazatelji OECD-a obuhvaćaju četiri važna područja: 1. utjecaj ekonomskih, ekoloških i društvenih čimbenika na odnos poljoprivrede i okoliša, 2. odnos između različitih poljoprivrednih praksi i njihov utjecaj na okoliš, osobito kretanje upravljanja poljoprivrednim gospodarstvima (npr. ekološka poljoprivreda, upravljanje hranjivim tvarima, štetočinama, zemljom i navodnjavanjem), 3. praćenje kretanja u korištenju poljoprivrednih inputa, (npr. mineralnog gnojiva, stajskog gnojiva), pesticida (uključujući rizike), vode i dr., 4. praćenje razmjera utjecaja poljoprivrede na kvalitetu tla, vode, očuvanje zemljišta, stakleničke plinove, biološku raznolikost, staništa divljih životinja i krajolik.

Uspješnost primjene agrookolišnih mjera će u budućnosti (2021. -2027.) biti prikazana kroz tzv. izlazne pokazatelje, tj. pokazatelje izravne povezanosti troška s rezultatom (npr. kolika je poljoprivredna ili šumska površina u ha pokrivena agrookolišnim mjerama ili koliko je korisnika uključeno). Toće ujedno doprinijeti poboljšanju nadzora u kraćem vremenskom razdoblju, dok još nisu vidljivi dugoročni ciljevi (npr. poboljšanje biološke raznolikosti) (Meredith i Hart, 2019) 


\section{AGROOKOLIŠNI POKAZATELI U DRŽAVAMA ČLANICAMA}

U ovom poglavlju odabrano je nekoliko agrokolišnih pokazatelja dostupnih za sve države članice EU u svrhu procjene koje države članice svojom poljoprivrednom proizvodnjom vrše najveći pritisak na okoliš. Odabir pokazatelja vršen je prema dva kriterija: zadnja dostupna godina, tj. zadnji službeni podatak i svojstvo relativnosti (pokazuju odnos između promatranih pojava). Valja imati da umu da se zadnja dostupna godina razlikuje kod različitih pokazatelja, međutim to je zadnji službeni podatak baze Eurostat i kao takav služi kao podloga za donošenje političkih odluka. Zbog preglednosti Tablice 1 imena pokazatelja su pod brojevima: (1) Korištena poljoprivredna površina (KPP) pod NATURA 2000 u 2016. (\%), (2) Povećanje/smanjenje udjela površine pod ekološkom poljoprivredom u 2017. u odnosu na 2012. godinu (\%), (3) Udio korištene energije u poljoprivredi u 2017 (\%), (4) Uvjetno grlo po hektaru u 2016., (5) Dušična bilanca (kg N po ha KPP) u 2015. godini, (6) Fosforna bilanca (kg P po ha KPP), trogodišnji prosjek 2013.-2015. i (7) Emisije plinova po KPP (kilotona $\mathrm{CH}_{4}$ i $\mathrm{N}_{2} \mathrm{O}$ na 1000 ha).

Tablica 1. Odabrani agrookolišni pokazatelji zemlja članica EU-28

Table 1 Selected agri-environmental indicators of EU-28 member states

\begin{tabular}{|c|c|c|c|c|c|c|c|}
\hline $\begin{array}{l}\text { Članica EU/ } \\
\text { Pokazatelj }\end{array}$ & (1) & (2) & (3) & (4) & (5) & (6) & (7) \\
\hline Belgija & 7,2 & 39,8 & 2,4 & 2,8 & 132 & 5,4 & 7,4 \\
\hline Bugarska & 22,4 & 249,1 & 1,8 & 0,2 & 28 & $-6,9$ & 1,2 \\
\hline Češka & 6,6 & 5,9 & 2,6 & 0,5 & 98 & $-2,6$ & 2,3 \\
\hline Danska & 4,7 & 16,2 & 4,3 & 1,6 & 80 & 7,4 & 3,8 \\
\hline Njemačka & 10,6 & 18,6 & : & 1,1 & 82 & $-2,2$ & 3,8 \\
\hline Estonija & 5,7 & 38,3 & 4,7 & 0,3 & 22 & $-7,2$ & 1,3 \\
\hline Irska & 3,7 & 40,8 & 2,0 & 1,3 & 42 & 4,5 & 4,2 \\
\hline Grčka & 18,7 & $-11,3$ & 1,8 & 0,5 & 59 & 1,0 & 1,6 \\
\hline Španjolska & 16,8 & 18,5 & 3,0 & 0,6 & 39 & 3,6 & 1,5 \\
\hline Francuska & 8,3 & 69,2 & 2,7 & 0,8 & 42 & 1,1 & 2,6 \\
\hline Hrvatska & 25,7 & 202,8 & 3,0 & 0,5 & 65 & 4,4 & 1,6 \\
\hline Italija & 10,8 & 63,5 & 2,4 & 0,8 & 66 & $-1,2$ & 2,3 \\
\hline Cipar & 6,1 & 43,2 & 2,9 & 1,5 & 194 & 31,2 & 4,4 \\
\hline Latvija & 6,6 & 37,4 & 4,8 & 0,3 & 28 & 2,2 & 1,4 \\
\hline Litva & 4,6 & 49,6 & 2,1 & 0,3 & 25 & 1,6 & 1,5 \\
\hline Luksemburg & 21,1 & 31,8 & 0,7 & 1,3 & 129 & 4,1 & 5,1 \\
\hline Mađarska & 14,7 & 52,9 & 3,4 & 0,5 & 39 & $-1,3$ & 1,2 \\
\hline Malta & 7,9 & 10,8 & 1,0 & 9,0 & 147 & 29,1 & 5,6 \\
\hline Nizozemska & 4,3 & 17,0 & 8,2 & 3,8 & 189 & 3,0 & 10,4 \\
\hline Austrija & 11,5 & 16,4 & 2,0 & 0,9 & 41 & 2,3 & 2,6 \\
\hline Poljska & 11,5 & $-24,5$ & 5,6 & 0,7 & 48 & 1,9 & 2,0 \\
\hline Portugal & 18,1 & 26,4 & 2,4 & 0,6 & 41 & 4,7 & 1,8 \\
\hline Rumunjska & 12,7 & $-10,3$ & 2,2 & 0,4 & 9 & $-1,4$ & 1,3 \\
\hline Slovenija & 23,2 & 31,7 & 1,5 & 1,0 & 45 & 2,9 & 3,6 \\
\hline Slovačka & 16,0 & 15,1 & 1,4 & 0,3 & 38 & $-5,8$ & 1,5 \\
\hline Finska & 1,2 & 30,8 & 2,9 & 0,5 & 49 & 3,9 & 2,8 \\
\hline Švedska & 4,1 & 20,8 & 1,0 & 0,6 & 32 & 0,3 & 2,2 \\
\hline UK & 2,5 & $-15,6$ & 1,0 & 0,8 & 83 & 5,5 & 2,5 \\
\hline
\end{tabular}

Izvor/Source: Eurostat, Agri-environmental indicators 
Udio korištene poljoprivredne površine pod područjima ekološke mreže „Natura 2000“ je najviši u Hrvatskoj (25,7 \%) Bugarskoj (25,7 \%), Sloveniji $(23,2$ \%) dok je najniži u Finskoj $(1,2 \%)$ i Ujedinjenom kraljevstvu (2,5\%). Između 2012. i 2017. najveći porast poljoprivrednih površina bilježe Bugarska i Hrvatska (preko $200 \%$ ). Ipak, četiri zemlje članice bilježe smanjenja površina pod ekološkom poljoprivredom: Rumunjska (-10,3 \%), Grčka (-11,3 \%), Ujedinjeno Kraljevstvo $(-15,6 \%)$ i Poljska (-24,5 \%).

Potrošnja energije u okviru poljoprivredne proizvodnje iznosi 2,8 \% ukupne potrošnje energije u EU-28 u 2017. godini. Najveći udio korištene energije u poljoprivredi ima Nizozemska (8.2 \%) i Poljska (5.6\%). Nizozemska također prednjači i u pritisku stočne proizvodnje na okoliš s 3,8 \% stočne jedinice po ha u 2016. Slijede Malta i Belgija s 2,9 i 2,8 stočnih jedinica po ha. Najnižu gustoću pokazuju Bugarska $(0,2)$, Slovačka i tri Baltičke zemlje s 0.3 stočne jedinice po hektaru. Nizozemska, Belgija, Malta i Luksemburg bilježe najviše emisije plinova po ha korištene poljoprivredne površine, čak dva puta više nego je prosjek EU.

Prema autorima koji su dublje analizirali problematiku zemalja članica kao onečišćivača okoliša poljoprivrednom proizvodnjom (Van Grinsven et al., 2019) države članice koje vrše najveći pritisak na okoliš zbog svojih poljoprivrednih proizvodnji su Nizozemska, Belgija, Njemačka, Francuska i Italija, dok najmanji okolišni pritisak vrše Litva, Latvija i Slovačka. Manji pritisaku budućnosti ujedno znači i smanjivanje poljoprivredne proizvodnje, osobito stočarske što može imati za posljedicu povećanje iste proizvodnje u nekim drugim, najčešće središnjim ili istočnim zemljama EU ili u svijetu radi zadovoljenja potražnje. Stoga se pritisak mora smanjiti potpuno novim, pravodobnim mjerama poljoprivredne politike, osmišljavanjem poljoprivredno-prehrambenih sustava s najmanjom mogućom potrošnjom resursa i emisijama plinova, promjenama prehrambenih navika, boljim upravljanjem hranidbenim otpadom i dr.

\section{Zaključak}

Zaključci ovog rada su:

Kompleksni odnos poljoprivrede i okoliša može biti pozitivan i negativan. Naime, poljoprivreda pozitivno utječe na izgled krajolika, na ssprječavanje prirodnih katastrofa, ali ujedno uzrokuje i eroziju tla, krčenje šuma, emisiju štetnih plinova i gubitak biološke raznolikosti.

Europska unija kroz svoju Zajedničku poljoprivrednu politiku prednjači u donošenju agrookolišnih mjera s obzirom da je poljoprivreda značajan onečišćivač okoliša.

Agrookolišni pokazatelji koji služe za procjenu učinaka mjera su brojni i osmišljeni kroz razne suradnje Eurostata i nekoliko važnih europskih i svjetskih institucija: OECD, EEA, JRC, NATURA itd.

Analiza odabranih agrookolišnih pokazatelja svih članica EU kroz Eurostat, pokazala je da ekonomski učinkovitije članice u poljoprivredno-prehrambenom sektoru ujedno vrše i najveći okolišni pritisak.

Buduća Zajednička poljoprivredna politika (2021. - 2027.) daje naglasak na strožem praćenju povezanosti troškova s izlaznim rezultatima i većim nagradama za primjenu dobrih agrookolišnih praksi na razini države članice i na razini poljoprivrednog gospodarstva. Unutar postojećih dobrih poljoprivrednih i okolišnih praksi (GAEC) dodana su tri nova uvjeta, a ukidaju se aktualna zelena plaćanja i višestruka sukladnost. Uvode se tzv. „eko-sheme“, a postojeće agrookolišne mjere se osnažuju mjerama borbe protiv klimatskih promjena.

\section{Literatura}

EC (2015): Okvir za nadzor i evaluaciju Zajedničke poljoprivredne politike za razdoblje 2014.-2020. Luxembourg: Ured za publikacije Europske unije, 2015. URL: http://publications.europa.eu/resource/cellar/00da6abf-7c75-11e59fae-01aa75ed71a1.0012.03/DOC_1 (11.11. 2020.) 
EC (2017): Technical handbook on the monitoring and evaluation framework of the Common Agricultural Policy 2014 - 2020. DG-AGRI URL: https://ec.europa.eu/info/sites/info/files/food-farming-fisheries/key_policies/documents/ technical-handbook-monitoring-evaluation-framework_june17_en.pdf

Eurostat: Agri-environmental indicators URL: https://ec.europa.eu/eurostat/web/agriculture/agri-environmentalindicators (11. 11. 2020.)

Gocht, A., Ciaian, P., Bielza, M., Terres, J. M., Roder,N., Himics, M., Salputra, G. (2017) EU-wide Economic and Environmental Impacts of CAP Greening with High Spatial and Farm-type Detail, Journal of Agricultural Economics, 68(3), 651-681. DOI: https://doi.org/10.1111/1477-9552.12217

Kelly, E. Latruffe, L. Desjeux, Y., Ryanc, M., Uthesd, S., Diazabakana, A., Dillon, E., Finn, J. (2018) Sustainability indicators for improved assessment of the effects of agricultural policy across the EU: Is FADN the answer? Ecological Indicators, 89, 903-911. DOI:

https://doi.org/10.1016/j.ecolind.2017.12.053

Kim, H., Kim, H. Madhavan, M., Suarez, A (2013) Measuring Environmental Externalities to Agriculture in Africa. Report on Framework Methodology. Case Study: Ghana Palm Oil Sector. George Washington University and FAO. URL: https://elliott.gwu.edu/sites/g/files/zaxdzs2141/f/downloads/acad/ids/ghana-palm-oil-case-study.pdf (11. 11. 2020.)

Matthews, A. (2013) Greening agricultural payments in the EU's Common Agricultural Policy. Biobased and Applied Economics 2(1), 1-27. https://doi.org/10.22004/ag.econ.149214

Meredith, S., and Hart, K. (2019) CAP 2021-27: Using the eco-scheme to maximise environmental and climate benefits, report for IFOAM EU by IEEP. URL: https://ieep.eu/publications/cap-2021-27-using-the-eco-scheme-to-maximise-environmental-and-climate-benefits (11. 11. 2020.)

Bas-Defossez, F. and Meredith, S. (2019) CAP 2021-27: A comparative analysis of the environmental performance of the COMENVI and COMAGRI reports on the Commission's proposals, report for NABU by IEEP. URL https://ieep.eu/ uploads/articles/attachments/bcf16988-c14f-4049-a528-a1760dOf6efc/IEEP\%20AGRI\%20ENVI\%20analysis\%20September\%202019.pdf?v=63734829544 (11. 11. 2020.)

Mikuš, O., Ravlić, M., Hadelan, L., Jež Rogelj, M., Ljubaj, T. (2019) Uloga poljoprivredne politike u odnosu poljoprivrede i okoliša. U: Mioč, B. ; Širić, I. ur. Zbornik radova 54. hrvatskog i 14. međunarodnog simpozija agronoma, Vodice, Hrvatska, 17-22. 02. 2019. Zagreb: Sveučilište u Zagrebu Agronomski fakultet, 143-147.

OECD (2001) Agricultural Policies in OECD Countries: Monitoring and Evaluation 2000: Glossary of Agricultural Policy Terms, OECD. URL: https://stats.oecd.org/glossary/detail.asp?ID=79 (11. 11. 2020.)

Rametsteiner, E., Pülzl, H., Alkan-Olsson, J., \& Frederiksen, P. (2011) Sustainability indicator development - s cience or political negotiation? Ecological Indicators, 11(1), 61-70. https://doi.org/10.1016/j.ecolind.2009.06.009

Recanati F., Maughan C., Pedrotti M., Dembska K., Antonelli M. (2019). Assessing the role of CAP for more sustainable and healthier food systems in Europe: A literature review, Science of the Total Environment, 653, 908-919.

Wilson, G. A., \& Buller, H. (2001) The use of socio-economic and environmental indicators in assessing the effectiveness of EU agrienvironmental policy. European Environment, 11(6), 297-313. https://doi.org/10.1002/eet.273

Wieck, C., Hausmann, I. (2019) Indicators everywhere: The new accountability of agricultural policy? $172^{\text {nd }}$ EAAE Seminar „Agricultural policy for the environment or environmental policy for agriculture?” May 28-29, 2019. Brussels. Belgium. https://doi.org/10.22004/ag.econ.289722

Prispjelo/Received: 11.11.2020.

Prihvaćeno/Accepted: 23.11.2020

Review paper

\title{
Agri-environmental indicators and their application in Common Agricultural Policy (CAP)
}

\begin{abstract}
The relationship between agriculture and the environment is stimulating increasing public attention and seeking specific public policy responses. Given that decision-making process should be evidence-based it is necessary to design and monitor the indicators that serve to create appropriate agricultural and environmental improvement measures. The paper provides an overview of the measures and chosen agrienvironmental indicators of all Member States (EU-28) for the available years in period 2012-2017 based on Eurostat data. Among other things, the results show that Croatia, Bulgaria and Slovenia are the leaders in the utilized agricultural area under the Natura 2000 ecological network. Member States that have the most developed agricultural sector usually also exert the greatest environmental pressure. Thus, the Netherlands has the highest share of energy used in agriculture and puts the greatest environmental pressure on livestock production. Therefore, through the current reform, the Common Agricultural Policy (CAP) seeks to develop adequate and compromise agri-environment measures for the upcoming period 2021-2027.
\end{abstract}

Keywords: agriculture, environment, measures, indicators, Common Agricultural Policy (CAP) 